\title{
Resistir é viver. Notas sobre a luta política das mulheres curdas por uma sociedade antipatriarcal no século XXI
}

Resisting Is Living. Notes on the Kurdish Women's Political Struggle for an AntiPatriarchal Society in the 21st Century

Résister c'est vivre. Notes sur la lutte politique des femmes kurdes pour une société antipatriarcale au XXIe siècle

\section{Maria Florencia Guarche Ribeiro e Alfredo Alejandro Gugliano}

\section{OpenEdition}

\section{Journals}

Edição electrónica

URL: https://journals.openedition.org/rccs/11960

DOI: $10.4000 /$ rccs. 11960

ISSN: 2182-7435

\section{Editora}

Centro de Estudos Sociais da Universidade de Coimbra

Edição impressa

Data de publição: 1 setembro 2021

Paginação: 29-52

ISSN: 0254-1106

\section{Refêrencia eletrónica}

Maria Florencia Guarche Ribeiro e Alfredo Alejandro Gugliano, «Resistir é viver. Notas sobre a luta política das mulheres curdas por uma sociedade antipatriarcal no século xx|», Revista Crítica de Ciências Sociais [Online], 125 | 2021, publicado a 30 setembro 2021, consultado a 03 outubro 2021. URL: http://journals.openedition.org/rccs/11960 ; DOI: https://doi.org/10.4000/rccs.11960 


\section{Resistir é viver. Notas sobre a luta política das mulheres curdas por uma sociedade antipatriarcal no século XXI}

A proposta deste artigo é discutir as particularidades do movimento de mulheres no Curdistão e a sua contribuição no que concerne os debates sobre formas alternativas de democracia. Partimos do pressuposto de que essa experiência, junto com outras trajetórias identificadas com o feminismo decolonial e o feminismo negro, está redimensionando a luta das mulheres enquanto vanguarda de um novo tipo de movimento emancipatório. Os resultados deste estudo indicam que as ações de empoderamento e de benefício mútuas promovidas pela geração de redes associativas, incentivadas pela organização autônoma dos quadros femininos na guerrilha, alteraram a autopercepção das mulheres nas comunidades curdas. Desta forma, as dinâmicas de poder social e político previamente existentes na região vêm sendo modificadas.

Palavras-chave: Curdistão; feminismo; militância política; movimentos sociais; mulheres.

\section{Introdução}

Neste artigo propomos apresentar de forma introdutória as particularidades do movimento de mulheres no Curdistão e a sua contribuição no que concerne os debates sobre formas alternativas de democracia, e igualmente debater o papel dos setores considerados subalternos para a reinvenção da militância política. O fio condutor será a trajetória de organização deste movimento de mulheres e a sua relação com o movimento de libertação nacional do Curdistão.

Especialmente na Síria e no Iraque, a resistência das mulheres curdas frente ao Estado Islâmico vem atraindo atenção nos últimos anos. Tanto na mídia internacional quanto nos meios de comunicação alternativos, difundem-se imagens de guerrilheiras portando suas kalashnikovs e liderando frentes de combate. Contudo, nem sempre é explícito que por trás dessas imagens há um movimento que tem buscado, na construção 
de autonomia do seu povo, combater o patriarcado a partir do Oriente Médio (Dirik, 2015; Tank, 2017). Nesse sentido, para o propósito deste artigo, entendemos por movimento de mulheres curdas a organização das mulheres que se inicia em relação com o movimento de libertação nacional do Curdistão, capitaneado pelo Partido dos Trabalhadores do Curdistão (PKK, na sigla original) e que hoje se constitui em um movimento autônomo e de atuação transnacional.

Nesse contexto de guerra emergem diferentes movimentos independentistas curdos no século XX, entre os quais se encontram coletivos de mulheres que não lutam somente pela unificação e independência de seu país, mas almejam construir ao mesmo tempo uma nova sociedade anticapitalista e antipatriarcal - nisso reside a sua particularidade na região. A presença das mulheres na luta independentista já é conhecida, pois diversas ativistas têm se destacado no movimento de libertação nacional, ${ }^{1}$ cuja origem remete às décadas de 1960 e 1970.

Em 1984 foram formadas as primeiras unidades militares independentistas do PKK na Turquia, oportunizando a incorporação de mulheres às frentes de combate. A partir daí, houve um incremento gradual na participação política das mulheres curdas nos anos 1990, tendo ocorrido, em maior medida, devido ao recrudescimento dos conflitos na Turquia (Çaha, 2011; Açık, 2013; Güneşer, 2015; Bergikhani et al., 2018).

Atualmente, as militantes do PKK formam um dos maiores contingentes de mulheres armadas do mundo. Essa potência é representada pelas unidades femininas de guerrilha como as Unidades das Mulheres Livres (YJA-Star, na sigla original) e pelas outras brigadas de mulheres que atuam em Rojava, no Curdistão ocidental. Esse tipo de resistência desafia o caráter patriarcal da sociedade e dá novo significado à atuação das mulheres na guerra (Dirik, 2015; Düzgün, 2015).

Esse não é um caso inédito. Existiram, no século xx, diversos conflitos armados nos quais mulheres exerceram um importante papel militar. Todavia, no caso das mulheres curdas, chama a atenção a dimensão desse movimento que tenta produzir um modo de vida antipatriarcal, no contexto de sociedades fortemente repressoras contra as mulheres ou, como define Shahrazad Mojab (2003), uma região não só de genocídio, mas de "generocídio" (gendericide), isto é, na qual a violência contra a mulher se expressa como uma política de Estado, de comunidades religiosas e de comandos militares em contextos de guerra.

1 Para mais informações sobre este tema sugerimos consultar: Bruinessen (2001), Cansun (2014), Al-Ali e Tas (2018a), Çağlayan (2020). 
Consequentemente, o interesse por analisar o movimento de mulheres curdas não está somente na adesão das combatentes à luta armada ou da fundação de brigadas femininas. $\mathrm{O}$ foco nessa experiência reside em compreender a sua contribuição para a criação de um novo modo de vida na região, de um projeto centrado na formação de sistemas de administração autônomos orientados pela luta anticapitalista e antipatriarcal (Dirik, 2015; Shahvisi, 2018).

A base teórico-ideológica do movimento de mulheres curdas é o Confederalismo Democrático e a jineolojî, ou ciência das mulheres. Ambos são apresentados como principais contributos da luta curda, uma nova forma de organização política estruturada em valores éticos, ecológicos, antipatriarcais e democráticos (Akkaya e Jongerden, 2012; Düzgün, 2015; Öcalan, 2018; Al-Ali e Käser, 2020).

A partir desses preceitos, as militantes buscam estruturar um novo sistema político nos territórios autônomos, onde as mulheres são protagonistas. Uma das primeiras expressões dessa proposta ficou conhecida como o Contrato Social de Rojava, ${ }^{2}$ documento que tem como objetivo formular um novo sistema político-administrativo, adverso ao modelo governamental centrado no Estado-nação (Knapp e Jongerden, 2014; Shahvisi, 2018).

De um modo geral, o nosso artigo está organizado em três eixos. No primeiro pretendemos abordar a trajetória do movimento de mulheres curdas, desde a sua organização enquanto movimento social até ao seu engajamento na luta armada e nas disputas internas do PKK. No segundo eixo o nosso enfoque estará dirigido para a discussão de alguns princípios da organização política das mulheres curdas, notadamente o Confederalismo Democrático e a jinneolojî. Já no terceiro abordaremos a experiência de Rojava, espaço no qual muitos dos projetos elaborados pelas mulheres curdas se concretizaram em termos de um novo modelo de organização social.

Este trabalho é o resultado de uma pesquisa qualitativa que dialoga com o desenvolvimento de uma epistemologia feminista a partir da qual não somente as mulheres, mas outros grupos socialmente oprimidos, conquistam o seu espaço na história. O texto foi fruto, inicialmente, de uma ampla pesquisa bibliográfica sobre o movimento de mulheres curdas, técnica complementada pela realização de entrevistas com dirigentes do movimento na Europa e na América Latina entre os anos de 2016 e 2018.

2 Disponível em https://www.kurdishinstitute.be/en/charter-of-the-social-contract/. Consultado a 11.06.2021. 


\section{Breves aspectos históricos da questão curda}

O povo curdo está entre as etnias mais antigas do Oriente Médio (McDowall, 1996; Eppel, 2016). Organizados social e politicamente em formas complexas (desde comunidades tribais nômades até formações sociais urbanas não agrárias), o povo curdo é frequentemente retratado como nômade muçulmano (Mojab e Hassanpour, 2021). Sendo uma nação sem Estado, esta encontra-se distribuída entre as fronteiras da Turquia, Irã, Iraque, Síria e Geórgia, tendo sua história vinculada às dinâmicas geopolíticas da região.

Como parte do Império Otomano (1299-1923), as elites curdas buscaram ativamente participar das negociações ocorridas no fim da Primeira Guerra Mundial (Eppel, 2016). Com a assinatura do Tratado de Sèvres (1920) selou-se o armistício entre os Aliados e o Império Otomano, reconhecendo-se a autodeterminação do povo curdo. Porém, poucos anos mais tarde, a Conferência de Lausanne (1922) dissolveu o Império e revogou esse reconhecimento, cedendo o território reivindicado pelos curdos para a recém-formada República da Turquia. Esse é o ponto de partida da chamada questão curda, conflito que se tem desenvolvido por todo o século Xx, até hoje. Com o transcorrer da mobilização política, também armada, do povo curdo, um dos aspectos que ganhou grande relevância foi a participação das organizações das mulheres curdas nesse processo, tema que trataremos de seguida.

\subsection{A experiência da luta armada}

O envolvimento das mulheres com o PKK se diferencia de outras experiências igualmente voltadas para a luta pela libertação nacional na região (Bergikhani et al., 2018; Ferreira e Santiago, 2018). Sua particularidade está em dois aspectos. Primeiro, porque tratar-se-ia da inserção precoce das mulheres na luta armada pela unificação e independência do Curdistão. Segundo, porque essa mobilização de mulheres na luta independentista resultou na introdução de uma pauta política antipatriarcal no interior das unidades de guerrilha (Al-Ali e Tas, 2018a; Dirik, 2018) - um fato incomum, mesmo em experiências com caráter semelhante em nível internacional.

O primeiro aspecto referido corresponde aos anos iniciais de atuação do partido, na década de 1980, caracterizando-se pela busca da unificação e independência do Curdistão por meio da luta armada. Nessa etapa, as mulheres se incorporaram de forma gradual e sucessiva às linhas de frente da guerrilha e se tornaram parte do movimento de libertação nacional. Decorreu dessa inclusão um questionamento inicial do sistema patriarcal e das especificidades do lugar social ocupado pelas mulheres no projeto de libertação nacional (Cansiz, 2017), crítica que incentivou a produção 
de espaços exclusivos para a articulação sociopolítica das mesmas, e da construção teórico-ideológica de argumentos que questionam o caráter sexista do militarismo, a partir dos anos 1990 (Al-Ali e Tas, 2018a; Bergikhani et al., 2018; Chaguri e Paniz, 2019).

O segundo aspecto mencionado condiz com o aprofundamento dos debates sobre o caráter substancial da dominação masculina na região, precisamente aquilo que é a mais contundente particularidade do movimento curdo. Na percepção das integrantes do movimento de mulheres curdas, a família desempenha um papel fundamental na manutenção das estruturas de dominação masculina, sendo considerada como um pequeno reino do patriarca (Öcalan, 2016b). Há, portanto, consciência da existência de um contrato sexual que legitima e naturaliza a violência e submissão das mulheres em contextos em que a dominação masculina pauta relações de poder e a hierarquia entre os gêneros. Sendo assim, a subversão das estruturas patriarcais esteve presente, ainda que em menor medida, desde os primórdios das organizações de mulheres na região.

Fruto de diversas discussões fomentadas pelos grupos de mulheres curdas que desenvolviam suas atividades dentro e fora da guerrilha, foi fundada na Alemanha, em 1987, a União das Mulheres Patrióticas pelo Curdistão (YJWK, na sigla original). A criação dessa entidade, focada a reivindicar um Curdistão independente a partir da contestação dos papéis de gênero nas organizações políticas curdas, foi mais um passo adiante para o aprofundamento dessas questões na luta pela libertação nacional. Em pouco tempo, a organização passou a vincular a ação de militantes da diáspora (Europa) e do Oriente Médio, ultrapassando as fronteiras da Turquia. Nesse sentido, desde a sua fundação que a organização atuou de maneira transnacional, tanto no Curdistão turco quanto junto às comunidades curdas refugiadas na Europa.

Com a formação das primeiras unidades de guerrilha em 1984, muitas jovens se engajaram nas frentes de combate. Tal adesão teve como cenário a intensificação dos conflitos na Turquia, a repressão política aos movimentos sociais e as práticas discriminatórias que impactam a vida das mulheres. Nessas circunstâncias, integrar o PKK significava extrapolar os espaços da sociabilidade feminina e chegar à militância política dos espaços partidários (Miranda, 2016: 13 ss.)

A adesão à luta armada acabou se tornando um importante canal de contestação da opressão feminina na região. Logo, nas montanhas do Curdistão, não faltam histórias de mulheres que se uniram às linhas de frente do PKK para fugir de casamentos forçados, violência doméstica e reclusão (Akan, 1992; Al-Ali e Käser, 2020). 
Da adesão ao confronto armado brotou uma dupla representação dessas militantes junto à sociedade curda: por um lado, são mulheres que superam os papéis sociais impostos pelo patriarcado, muitas vezes assumindo a condição de heroínas na construção de um Curdistão livre; por outro, são guerrilheiras que fomentam uma cultura militarizada a partir da qual a mudança social só é compreendida por meio do uso da força militar, sustentando a ideia de que resistência e luta fazem parte da identidade histórica da mulher curda (Bergikhani et al., 2018).

Tais representações estão presentes no dia a dia das militantes curdas, sobretudo a partir da criação das unidades de proteção de defesa em Rojava, cujo lema é: resistência é vida. Isto é, assim, o reconhecimento do papel ativo das mulheres curdas enquanto uma força de resistência contra as diversas opressões presentes na sociedade.

A presença ativa das mulheres no combate favoreceu seu reconhecimento entre os guerrilheiros, estimulando a organização de espaços autônomos e tensionando as bases ideológicas dos partidos, que logo passaram a considerar a questão de gênero (Al-Ali e Tas, 2018a). A partir de 1993 formaram-se as primeiras unidades combatentes compostas exclusivamente por mulheres, como a União das Mulheres Livres do Curdistão (YJAK, na sigla original), mais tarde chamada de YJA-Star. Entre os objetivos desse agrupamento se destaca o rompimento com a socialização patriarcal-feudal presente nas comunidades curdas (Düzgün, 2015).

Sobre esse contingente, Aliza Marcus (2007) estima que, já em 1993, um terço das forças armadas do PKK era composto por mulheres. $\mathrm{Na}$ guerrilha, o abandono da vida na comunidade e o rompimento com os papéis tradicionais de gênero abriram caminhos para que as mulheres curdas passassem a reivindicar a transformação de todos os aspectos das suas vidas (Knapp et al., 2016).

\subsection{A organização política das mulheres curdas}

Além do envolvimento na luta armada, o movimento também avançou no tocante à ocupação de espaços na esfera partidária. $\mathrm{O}$ primeiro partido das mulheres curdas foi fundado em 8 de março de 1999: o Partido das Mulheres Trabalhadoras do Curdistão (PJKK, na sigla original). Após várias mudanças em 2002, o partido passou a se chamar Partido da Libertação da Mulher (PJA, na sigla original), tendo sido apresentado um novo programa político sob o título: "Contrato Social da Mulher" (Çağlayan, 2020). Tendo como base esse documento, o partido assumiu para si a responsabilidade de articular a luta das mulheres curdas com outras mobilizações desenvolvidas por movimentos feministas em diferentes partes do mundo. 
Nasceu daí a tentativa de criar uma proposta confederativa de organização do movimento de mulheres, articulando tanto grupos de ativistas nacionais quanto internacionais vinculados à causa curda (Women's Movement of Kurdistan, 2020).

O referido documento apresentou as regras internas do partido e os princípios que deveriam orientar o trabalho das instituições afiliadas, priorizando a democracia direta na tomada de decisões e a horizontalidade nas relações sociopolíticas, tanto orgânicas quanto nas estruturas de base da sociedade. Buscou-se, dessa maneira, ampliar o diálogo social e fomentar atividades visando a promoção dos direitos humanos, da paz e da democracia participativa.

As transformações no partido foram uma tentativa de aprofundamento programático em relação às experiências anteriores, tendo como objetivo a formação de quadros femininos do partido, trabalhando na esfera ideológica, acadêmica e cultural. Entre suas responsabilidades estava o desenvolvimento de pesquisas no campo dos estudos sobre mulher e gênero, bem como a promoção da auto-organização da sociedade, contribuindo para a implementação de redes associativas entre as mulheres da comunidade e aperfeiçoamento da jineolojî.

Outro grupo importante na organização do movimento de mulheres foi a já referida YJAK. Seguindo um modelo organizativo horizontal e flexível, teve forte atuação nas montanhas de Qandil, no norte do Curdistão do Iraque. Tendo como objetivo a atuação transnacional nas quatro partes do Curdistão (Turquia, Síria, Irã e Iraque), a organização elencava entre suas responsabilidades a proposição do desenvolvimento de uma sociedade democrática por meio dos princípios da organização autônoma feminina e da unificação do Curdistão em um modelo confederado, realizando trabalho de base nas aldeias e comunidades isoladas no meio rural e nas periferias urbanas (Çağlayan, 2020). Ademais, o movimento atua diretamente no combate às tradições misóginas, entre elas, os crimes de honra e os casamentos arranjados ainda comuns nessas regiões.

Indo além das estruturas partidárias, foi fundado o Alto Conselho das Mulheres (KJB, na sigla original) em abril de 2005, uma instituição guarda-chuva que tem como objetivo a formação de uma unidade confederada nas quatro partes do Curdistão, incluindo as diversas organizações de mulheres do PKK, como as unidades de autodefesa, as assembleias, as associações autônomas, etc. A partir de 2014, essa organização passou a compor a Comunidade das Mulheres Curdas (KJK, na sigla original), unificando as diferentes articulações de mulheres da região. ${ }^{3}$ Como vimos, o movimento

3 Mais informação em https://www.kjkonline.net/en/hakkimizda/. Consultado a 20.06.2021. 
de mulheres curdas se estrutura a partir de uma ampla rede de organizações. Assim, existe por exemplo a YJAK que, para além de estar voltada para a organização social e política das mulheres, desenvolve um intenso trabalho enquanto braço de autodefesa e proteção militar e, também, estruturas como o Partido das Mulheres Livres do Curdistão (PAJK, na sigla original), que atua fundamentalmente no campo ideológico. Uma síntese temporal da criação das organizações pode ser vista na Figura 1.

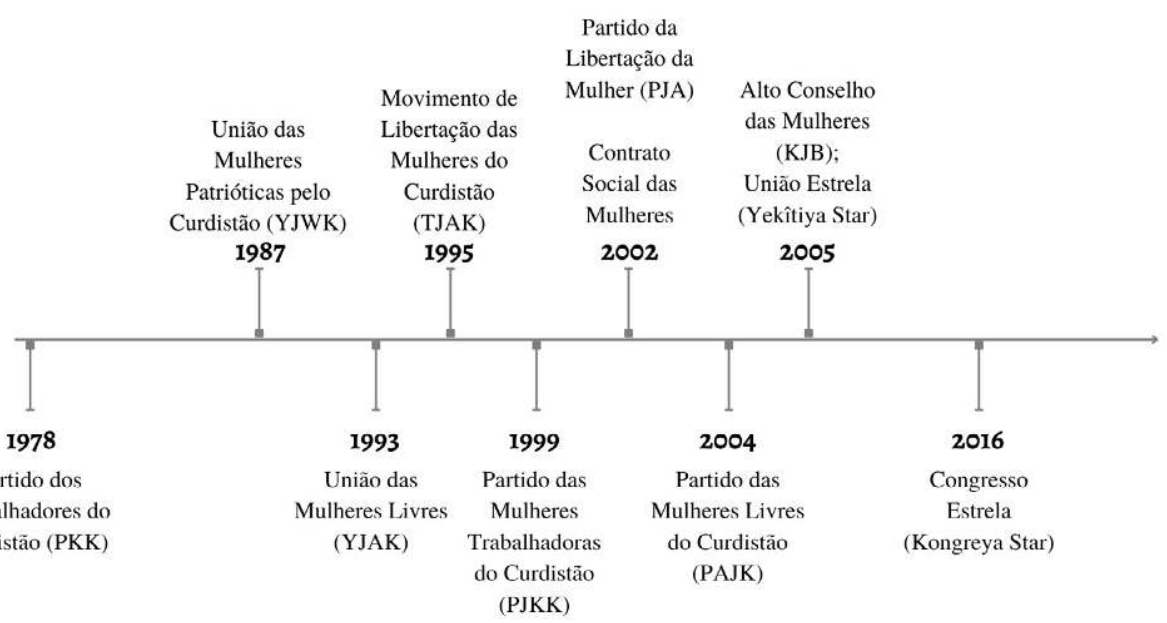

FIGURA 1 - Linha do tempo da fundação das organizações de mulheres curdas

Fonte: elaboração própria.

Entre as iniciativas adotadas para aumentar a participação feminina nas organizações curdas está a inclusão de cotas para a incorporação de mulheres nos partidos políticos, organização de grupos de planejamento para inserção de uma agenda de gênero, e também a obrigatoriedade de implementação da liderança compartilhada (Knapp et al., 2016).

A luta das mulheres curdas não representa simplesmente um novo ativismo baseado na inserção militar, mas se traduz também na tentativa de construir uma sociedade radicalmente anticapitalista e antipatriarcal, centrada em uma epistemologia feminista (Al-ali e Tas, 2018b). Quiçá nisso resida uma das principais características desse movimento, a sua capacidade de articular a prática política com a formulação de um conjunto de princípios que fundamentam uma intervenção autônoma das mulheres por meio do Confederalismo Democrático e da jineolojî. 


\section{A ciência das mulheres}

Partimos do pressuposto de que a experiência de luta das mulheres curdas, junto com outros movimentos identificados com o feminismo decolonial e o feminismo negro, tem construído um movimento emancipatório de um novo tipo. A jineolojî, o princípio que oferece substância à organização das mulheres curdas, advém da união entre a raiz jin, que significa mulher ou vida no idioma kurmanjî, com o radical logos, que em grego poderia ser traduzido como discurso ou razão (Comité de Jineologî, 2017; Neven e Schäfers, 2017).

Para as curdas é a ciência da vida ou, como mais comumente é conhecida, a ciência das mulheres. Desse radical, também derivam as palavras curdas jindar e jinda, que podem ser traduzidas como vivacidade/vigor e vivificante/ /estimulante, respectivamente (Diyar, 2021). Segundo Eleonora Gea Piccardi (2021), a jineolojî nasceu concretamente em 2011 quando os primeiros comitês foram fundados e, com eles, foram criadas academias de pesquisa, escolas e projetos de base voltados para o desenvolvimento desta ciência.

É uma perspectiva que se soma às outras formas de pensamento radical que Boaventura de Sousa Santos (2019) identifica como pós-abissal, isto é, representa uma ruptura com o modelo ocidental de pensamento e ação. Nesse sentido, o movimento curdo sublinha que a jineolojî vem preencher um vazio nas ciências sociais ocidentais e sua tendência à universalização das relações sociais (Düzgün, 2015). Representando uma contribuição central para o redimensionamento do debate sobre o feminismo, sendo mais do que uma teoria feminista, a jineolojî potencializa uma nova compreensão da emancipação social, apontando para formas de democracia radicais (Akkaya e Jongerden, 2012).

Todavia, a mobilização das mulheres curdas não significa uma afiliação direta ao feminismo, ${ }^{4}$ pois no movimento alguns setores ainda reivindicam uma forte crítica a um modelo de feminismo liberal, capitaneado pelo pensamento ocidental hegemônico (Akan, 1992). Nos dias de hoje poder-se-ia dizer que não há um posicionamento homogêneo a respeito da filiação do movimento de mulheres curdas ao feminismo, pois, no interior do movimento, segmentos se posicionam criticamente a respeito do que consideram uma falta de radicalidade de um feminismo hegemônico, composto por mulheres que em grande parte fazem parte da elite social no mundo ocidental (Comité de Jineologî, 2017). Mesmo assim, a jineolojî aposta nas epistemologias feministas que criticam as ciências sociais e

\footnotetext{
4 Para mais informações sobre o movimento de mulheres curdas e o feminismo na Turquia, recomendamos Çaha (2011).
} 
que "desmascaram o patriarcado" (Diyar, 2021), criando uma proposta epistemológica ao mesmo tempo anticolonial, antissistêmica, coletiva e transnacional.

Sua visão anticolonialista dificulta a plena identificação com um tipo de feminismo visto como parte de um projeto hegemônico e colonizador, como afirma, em entrevista, Necîbe Qeredaxî (in Neven e Schäfers, 2017). Crítica semelhante à desenvolvida desde a ótica do feminismo das mulheres negras, por meio do seu aporte teórico-metodológico intersecional, que aponta para a pouca visibilidade que o racismo ocupa nas pautas reivindicativas do feminismo hegemônico. Dessa forma, consideramos que a principal semelhança entre o movimento de mulheres curdas e o feminismo negro é que ambas são perspectivas que revelam a potência organizativa dessas parcelas de mulheres que estavam ocultas das dinâmicas sociais e políticas centralizadas nas experiências das feministas brancas, do centro do mundo.

Contudo, a principal diferença que se pode perceber é o protagonismo que o movimento de mulheres do Curdistão assume nas organizações vinculadas à luta curda na região. Dessa forma, elas se tornam um referencial não só para o debate de gênero dentro do partido, mas se propõem a construir um projeto revolucionário que vai além das questões do povo curdo, incluindo mulheres de distintos grupos étnicos e religiosos na região. A jineolojî emerge enquanto projeto global que reconhece as diferenças e se propõe a subverter as relações de poder a nível estrutural e sistêmico.

A crítica aos movimentos hegemônicos foi o primeiro passo para a elaboração do que as organizações de mulheres curdas denominam "teoria da ruptura", um deslocamento político e epistemológico que propõe o fim da hegemonia do "macho dominante" (Kaya, 2015; Öcalan, 2016b). Nesse sentido, a proposta de ruptura epistêmica com a ciência positivista as aproxima das concepções apresentadas por autoras como Sandra Harding (1993, 1996, 2012), bell hooks (2000) e Patricia Hill Collins (1997, 2000, 2018), pensadoras que destacam a importância da valorização de epistemologias feministas centradas no reconhecimento do chamado "ponto de vista". Frente a isso, pode-se dizer que o movimento de mulheres do Curdistão se aproxima dos chamados movimentos feministas terceiro-mundistas, aqueles que consideram uma abordagem interseccional como base da sua matriz teórica (Ferreira e Santiago, 2018).

A representação da jineolojî, uma imagem da deusa Ishtar segurando um fuso de fiar, representa essa autonomia. A deusa desembaraça a história e oferece o fio de ligação entre si mesma e a sociedade comunal. A figura representa a conexão das mulheres com a sua ancestralidade, sendo considerado elemento fundador da sociedade anterior à formação das primeiras civilizações. 
Desse modo, encoraja as mulheres a criar suas próprias organizações e disciplinas, incentivando uma interpretação coletiva e feminina a respeito dos processos políticos, sociais e históricos do povo curdo.

Enquanto conceito, a jineolojî aparece pela primeira vez em 2008 nos escritos reunidos no livro Sociology of Freedom de Abdullah Öcalan, principal liderança curda, onde é apresentado como a matriz do pensamento antipatriarcal do Confederalismo Democrático (Öcalan, 2020). O conceito é apropriado pelas mulheres e se transforma em um instrumento em prol da promoção de alternativas para o rompimento com a mentalidade da masculinidade hegemônica em todas as esferas sociais (Pavicic-Ivelja, 2016). Segundo os seus princípios, a transformação radical da sociedade se dará a partir da intervenção profunda na mentalidade e nos paradigmas patriarcais, visando o acesso das mulheres a todos os âmbitos sociais, o que será conquistado por meio da participação direta e ativa na esfera política e científica.

Ao romper com os pressupostos da ciência tradicional, a ciência das mulheres assume a função de construir uma ciência não sexista e não androcêntrica, se aproximando do que algumas autoras identificaram como crítica feminista ao modelo de ciência tradicional (Bandeira, 2008; Giordano, 2017; Rivers, 2019). Isto poderia levar à formação de uma nova perspectiva científica feminista não excludente, articulada com todas as outras ciências e epistemologias críticas, ou pós-abissais (Santos, 2019).

A necessidade de formular um projeto crítico de reinterpretação coletiva da ciência, voltado para a transformação social, aproxima a jineolojî da teoria feminista crítica e sua caracterização sobre as particularidades do ponto de vista dos oprimidos. Por isso, a ciência das mulheres se desenvolveu a partir das iniciativas e experiências da organização do movimento de mulheres do Curdistão, e diz respeito diretamente ao processo de subjetivação das mulheres curdas e serviu como ponto de virada do movimento (Piccardi, 2021). Com o tempo, foi incorporando diferentes movimentos, tornando-se elemento estruturante das organizações vinculadas ao movimento de libertação nacional do Curdistão e do autogoverno na Federação Democrática do Norte e Leste da Síria.

Por meio do que podemos chamar de uma historiografia feminista (herstory) a jineolojî objetiva identificar o papel atribuído às mulheres nos diferentes períodos da humanidade propondo compreender suas especificidades e oferecer oportunidades para a elaboração de alternativas epistêmicas à dominação masculina e políticas centradas no modo de vida das mulheres (Comité de Jineologî, 2017). Em vista disso, a ação das mulheres e a elaboração de uma epistemologia crítica depende do estabelecimento de espaços voltados para a sua organização e empoderamento. 
A necessidade de incluir diferentes perspectivas e ampliar o número de participantes nesses espaços incentivou a criação de comitês de jineolojî em diferentes partes do mundo. $\mathrm{O}$ objetivo desses comitês está sendo o de continuar a desenvolver as bases teóricas e práticas dessa ciência e, ao mesmo tempo, construir laços internacionais entre movimentos de mulheres. É o caso do Comité de Mujeres en Solidaridad con Kurdistán na Argentina ou o Comitê de Mulheres: A Resistência é Vida, fundado em Porto Alegre, no Brasil, em 2015.

A fim de especificar a aplicação desses pressupostos na sociedade curda, as seções seguintes discutem o Confederalismo Democrático e descrevem a dinâmica do funcionamento das organizações de mulheres em Rojava, local onde os princípios do Confederalismo Democrático são implementados na formação do autogoverno da Federação Democrática do Norte e Leste da Síria.

\subsection{Confederalismo Democrático}

O Confederalismo Democrático é uma tentativa de renovar o debate sobre alternativas às instituições políticas tradicionais nos marcos das democracias liberais. Inspirado nas ideias da ecologia social e do municipalismo libertário de Murray Bookchin, propõe a organização de um sistema político sem a presença nem do Estado, nem de um governo centralizador, se baseando para isso num conjunto de assembleias e conselhos populares de representação de diferentes segmentos sociais (Gerber e Brincat, 2018).

Essa perspectiva inicialmente foi elaborada por Öcalan (2016a), para quem a proposta representa a possibilidade de uma administração política não-estatal ou democracia sem Estado. De acordo com o autor, os processos democráticos de tomada de decisão não deveriam ser confundidos com as políticas estatais, na medida em que enquanto o aparelho estatal funciona através de decretos, a democracia somente pode existir a partir do debate público e do consenso coletivo.

John Holloway (2003), numa proposição que caminha em direção semelhante, também sublinhou a impossibilidade de transformar o mundo por meio do Estado. Conforme o autor, pensar a transformação radical da sociedade deveria passar pela substituição do "poder-sobre" uma relação típica da ação estatal, pelo "poder-fazer", resgatando o poder da vida cotidiana na produção das ações públicas, substituindo a política do poder pelo poder da política.

Nesse sentido, o Confederalismo Democrático tem como princípios regulamentadores (entre outros): a união voluntária das instituições, das 
organizações e das mulheres; o compartilhamento da responsabilidade de coordenar, implementar e supervisionar as decisões políticas das diferentes instituições; a flexibilização e o respeito à diversidade na promoção da participação democrática. Para Sebastián Paredes este projeto é uma "teoria crítica e não uma solução apenas para os problemas" do povo curdo, já que tal proposta não se limita ao Curdistão, encorajando sua expansão para outras sociedades (Paredes, 2017: 95). De igual forma, Carlos Pazmiño (2017) sublinha que o Confederalismo Democrático é um paradigma teórico e tático que pretende ser a base do projeto da nação democrática, desmantelando as bases do Estado moderno.

Considerado como um dos principais instrumentos para unificação do povo curdo, o Confederalismo Democrático representa um ousado projeto de radicalização da autonomia política que envolve a formação de uma estrutura de base formada por assembleias locais que, por sua vez, elegem delegados para os conselhos municipais e assembleias regionais. Pelo menos desde 2005 que o PKK vem desenvolvendo esse projeto sob o nome de União das Comunidades do Curdistão, constituindo uma ampla rede de organizações enquanto alternativa ao formato tradicional de Estado-nação (Akkaya e Jongerden, 2014).

$\mathrm{Na}$ prática, o modelo político se dá por meio de uma democracia direta, que é complementada pela participação de delegados somente nos casos em que a problemática em questão foge da alçada da comunidade local. Nesse modelo não existe uma estrutura parlamentar responsável pelo poder legislativo, sendo essa função exercida por uma confederação de instituições que englobam partidos políticos, conselhos setoriais e temáticos (como o de mulheres e o do meio ambiente), assim como organizações da sociedade civil. Um projeto cuja adesão é baseada no local de residência e no qual o poder é exercido de baixo para cima, invertendo a lógica da moderna democracia representativa (Baris, 2020).

A proposta, enquanto um modelo inovador de administração política não estatal, possui cinco princípios: 1) o direito à autodeterminação dos povos; 2) a consideração do Confederalismo Democrático como um paradigma social e político não estatal, organizado no marco da "nação democrática" (Öcalan, 2018); 3) a organização política de base; 4) o caráter não independentista das instituições criadas sob este sistema, ou seja, o abandono do projeto de formação de novas unidades estatais, a partir da reivindicação da governança coletiva e autônoma das comunidades; e 5) o antinacionalismo, promovendo a integração democrática nas quatro partes do Curdistão sem questionar as fronteiras estatais (Öcalan, 2016a: 33-34 ss.). 


\section{A luta antipatriarcal em Rojava}

Rojava, também conhecida como Curdistão Ocidental, está localizada nas regiões norte e leste da Síria e, desde 2012, é uma região autônoma na qual são implementados os principais projetos do movimento curdo, tais como o Confederalismo Democrático, a igualdade de gênero, a ecologia radical e a democracia direta (Silva, 2017; Dirik, 2018; Schmidinger, 2018; Amorosi, 2019). Contando com mais de quatro milhões de habitantes, é o principal símbolo da luta antipatriarcal das mulheres na região a partir da intervenção do Congresso Estrela e a formulação de um conjunto de diretrizes que buscam fortalecer a perspectiva das mulheres na sociedade.

Na primeira metade da década de 2000 surgiram no Curdistão uma série de organizações políticas associadas aos princípios de despatriarcalização da sociedade, em grande parte, ideia promovida a partir dos debates sobre o Confederalismo Democrático envolvendo diferentes grupos. Assim, em 2005 foi fundada a União Estrela das Mulheres Livres (Yekîtiya Star, no original), uma organização voltada a atuar no território de Rojava. Sua criação visou responder às reivindicações de um efervescente movimento de mulheres que operava clandestinamente na região havia alguns anos.

A repressão do governo sírio às organizações curdas e as limitações impostas por uma sociedade patriarcal impedia o avanço das mobilizações de mulheres, obrigando as ativistas a agir na clandestinidade. Nesse contexto foi organizado na cidade síria de Qamislo, em 2007, o segundo congresso da União Estrela, e um terceiro, no ano seguinte, na cidade de Aleppo.

Em 2011 a organização deixou a clandestinidade e criou uma série de conselhos de mulheres nas cidades sírias de Damasco, Aleppo, Rakka e Haseki. O objetivo desses conselhos foi promover a formação política e o empoderamento das mulheres, convocando a participação na organização e gestão do autogoverno de Rojava. Com a declaração de autonomia dos cantões em Rojava e a formação da Federação Democrática do Norte e Leste da Síria, a União Estrela passou a agir como coordenadora do movimento de mulheres para todos os cantões. Por meio da realização de oficinas, de assembleias e da criação de academias dirigidas ao estudo da jineolojî, esta organização tornou-se referência para a implementação de iniciativas voltadas para a despatriarcalização da sociedade.

Em 2016 a União Estrela mudou de nome e passou a chamar-se Congresso Estrela, transformação que visou o reconhecimento e incorporação de mulheres de diversas etnias e religiões. Desse modo, a organização passou a fomentar valores de diversidade étnica, religiosa e linguística, transformando-se numa entidade autônoma que congregava organizações independentes numa confederação. 
Com a inserção na estrutura de administração pública da Federação Democrática do Norte e Leste da Síria, o Congresso Estrela também passou a organizar uma rede horizontal de comunas, assembleias, cooperativas e fundações estruturadas em espaços de participação direta. Entre suas esferas de ação, o destaque vai para as "casas das mulheres", que funcionam como centros de acolhimento e referência às mulheres vítimas de violência em diversas cidades do território autônomo. A primeira destas casas foi fundada em Qamishlo, no ano de 2011. Ações voltadas a impedir a ocorrência de casos de violência contra as mulheres, focadas no empoderamento feminino, fazem parte do trabalho desenvolvido em diversas dessas casas. Para se ter uma ideia da magnitude desse empreendimento, em novembro de 2016 foi realizada a primeira conferência das casas das mulheres, reunindo 135 representantes oriundas das cidades de Al-Jazeera, Afrin, Kobanê, Damasco e Manbij (Kongreya Star, 2018).

O sistema de justiça de Rojava também foi organizado de forma autônoma. No caso, as mulheres do Congresso Estrela possuem um Conselho de Mulheres para a Justiça Social. Esta organização visa o empoderamento das mulheres voltado para a resolução de conflitos a partir de uma perspectiva de gênero. Este conselho visita todas as organizações integrantes do governo autônomo, instituições sociais e judiciais e os supervisiona a partir de uma perspectiva sensível aos interesses das mulheres. Esses comitês são responsáveis pela coordenação das casas das mulheres e pela resolução de conflitos, quando necessário.

Sua agenda de trabalho é dividida, administrada e executada por meio de dez comitês: justiça, municipalidades e meio ambiente, arte e cultura, relações políticas, autodefesa, economia participativa, relações diplomáticas, educação, mídia, e relações sociais (comunidade civil). Todos estes comitês trabalham sob a orientação dos princípios da jineolojî e são administrados exclusivamente por mulheres.

O destaque entre os comitês vai para as associações e cooperativas criadas para a emancipação econômica das mulheres. O conceito de economia solidária é utilizado por essa organização com o objetivo de promover o empoderamento econômico das comunidades em um contexto de guerra e de embargo impetrado pela Turquia e pelo Iraque, países fronteiriços a Rojava.

De forma integrada com o comitê de municipalidades e meio ambiente desenvolvem-se alternativas para a ampliação da área produtiva de Rojava. Somente nas províncias de Al-Jazeera, Qamishlo, Amude e Derbesiye mais de 86 associações foram estabelecidas, empregando mais de 7000 mulheres de forma cooperativada. Em Hasaka, no nordeste da Síria, 300 mulheres têm 
à sua disposição seis mil hectares de terra para desenvolver cultivos agrícolas, uma amostra do grande esforço por constituir um sistema produtivo autônomo coordenado pelas mesmas (Kongreya Star, 2018).

\section{Considerações finais}

No final de 2019 ocorreu um recrudescimento dos combates na fronteira entre a Turquia e a Síria após a retirada das tropas ocidentais daquele território, uma reação que não apenas visava o esmagamento da luta pela independência do Curdistão, mas especialmente a exterminação do movimento de emancipação das mulheres curdas e a destruição da memória da sua existência na região. Este fato torna ainda mais urgente a discussão dos temas abordados aqui.

Neste artigo discutimos a trajetória do movimento de mulheres no noroeste do Curdistão a partir de sua articulação dentro do PKK e as respectivas derivações da mesma. Com o olhar direcionado às redes associativas de articulação formadas por mulheres, se buscou identificar as suas dinâmicas na construção da luta contra o patriarcado e em prol da emancipação das mulheres, observando a formação autônoma de suas próprias organizações e a disputa pelo reconhecimento de suas reivindicações no interior do partido.

Essas organizações se encontram vinculadas à questão curda, problema impulsionado por meio de acordos internacionais que dividiram o território do Curdistão em função do interesse das grandes potências mundiais no contexto da Primeira Guerra Mundial. Tais acontecimentos impactaram o desenvolvimento do movimento de libertação nacional, retratado aqui na figura do PKK.

A incorporação das mulheres à guerrilha e sua crescente organização em espaços exclusivos para mulheres favoreceram a percepção da necessidade de avançar nos debates a respeito da condição feminina na sociedade curda. A partir dessas experiências, as redes de apoio e a solidariedade entre as mulheres do partido e a comunidade ganharam força e ultrapassaram o Oriente Médio, formando uma importante rede internacional de solidariedade.

As ações de empoderamento e de benefício mútuos promovidas pela geração de redes associativas, incentivadas pela organização autônoma dos quadros femininos na guerrilha, alteraram a autopercepção das mulheres locais nas comunidades curdas. Com a valorização e a ressignificação da história por meio da jineolojî, a formação das redes associativas entre curdos e curdas vem sendo transformada através de dinâmicas sociais e políticas, transformando a cultura da região. 
A capitalização do engajamento político dessas mulheres incrementou exponencialmente o número de militantes na guerrilha. Assim, o PKK tornou-se palco das primeiras querelas sobre as hierarquias sociais presentes na sociedade curda, entre elas, a questão do sexismo. Esses debates impactaram a estrutura e as práxis do partido, tornando evidente as duras condições de vida que as mulheres enfrentam nas comunidades, em meio à guerra e à negação cultural.

Tais condições contrastam com o modo de vida promovido nas montanhas de Qandil, berço da guerrilha, onde a discriminação, a opressão e o sexismo se tornaram prioridades a serem combatidas pelas militantes, transformando as montanhas da região num espaço de oportunidades e visando a busca por liberdade e empoderamento.

O aumento qualitativo e quantitativo da participação das mulheres no partido teve igualmente importantes reflexos. A formação do PAJK e a difusão da ideologia da libertação das mulheres influenciou o trabalho de Abdullah Öcalan na formulação do Confederalismo Democrático. Desse modo, o ponto de vista das mulheres passou a ser reconhecido e incorporado na base ideológica partidária, em especial a partir do debate gerado pela ciência das mulheres.

Mesmo não assumindo plenamente essa identificação, a jineolojî é bastante próxima da epistemologia feminista, na medida em que reconhece a necessidade de reorganizar a sociedade e o conhecimento a partir das perspectivas apresentadas pela mobilização das mulheres. Decorre daí o empenho em estabelecer a ciência das mulheres como base epistêmica e política do autogoverno de Rojava. Contudo, essa perspectiva também se distancia do feminismo hegemônico do mundo ocidental, postulando críticas muito semelhantes àquelas que estão sendo formuladas, por exemplo, pelos feminismos negro, camponês e decolonial.

A elaboração da jineolojî evidencia o compromisso das organizações de mulheres curdas com a transformação radical da sociedade, apresentando uma proposta de intervenção profunda na própria mentalidade patriarcal. Dessa forma, as organizações políticas e sociais criadas em Rojava são, na prática, a aplicação do paradigma feminista em um governo autônomo. O Congresso Estrela é exemplo dessa afirmação, tendo sido a organização responsável pela institucionalização da jineolojî, garantindo a aplicação de seus princípios em todos os níveis da sociedade. Por meio desse espaço, o movimento de mulheres de Rojava ocupa um lugar significativo dentro do governo autônomo da região, congregando mulheres de diversas etnias, religiões, idades e culturas. Sua ação é decisiva para garantir a participação política das mulheres e a implementação da agenda de gênero na região. 
A incidência dessa organização vai muito além da inclusão de mulheres nas instâncias administrativas e políticas do autogoverno. Mais do que isso, é a principal responsável pela coordenação das cooperativas, órgãos de justiça e de todo o sistema de educação. Desse modo, pode-se dizer que o Congresso Estrela garante efetivamente que os princípios da jineolojî sejam postos em exercício no cotidiano da sociedade.

O governo autônomo formado em Rojava é resultado de 40 anos de luta e de organização das mulheres em busca do reconhecimento de direitos. Embora de início esse movimento tenha se articulado em torno das demandas independentistas, gradualmente a questão de gênero passou a ser elemento essencial da sua mobilização. O caráter antipatriarcal e a construção da autonomia democrática em estrutura horizontal, auto-organizada, tornam esta experiência um evento único na atualidade, um tema de estudo que demanda a atenção não somente das feministas, mas de todas as pessoas interessadas no futuro da democracia nas sociedades contemporâneas.

Revisto por Alina Timóteo

\section{Referências bibliográficas}

Açık, Necla (2013), "Re-defining the Role of Women within the Kurdish National Movement in Turkey in the 1990s", in Welat Zeydanlioglu; Cengiz Gunes (orgs.), The Kurdish Question in Turkey: New Perspectives on Conflict, Representation and Reconciliation. London: Routledge, 114-136.

Akan, Sara (1992), "Women in Kurdistan: A History of Their Struggle since the '70s", in Kurdistan Solidarity Committee (org.), Kurdish Woman: The Struggle for National Liberation and Women's Rights. Interviews and Articles. London: KSC-KIC Publications, 7-16.

Akkaya, Ahmet H.; Jongerden, Joost (2012), "Reassembling the Political: The PKK and the Project of Radical Democracy”, European Journal of Turkish Studies, 14. DOI: https://doi.org/10.4000/ejts.4615

Akkaya, Ahmet H.; Jongerden, Joost (2014), "Confederalism and Autonomy in Turkey: The Kurdistan Worker's Party and the Reinvention of Democracy", in Cengiz Gunez; Welat Zeydanhoglu (orgs.), The Kurdish Question in Turkey. Oxon: Routledge, 186-204.

Al-Ali, Nadje; Käser, Isabel (2020), "Beyond Feminism? Jineolojî and the Kurdish Women's Freedom Movement”, Politics \& Gender, 16(2), 1-32.

Al-Ali, Nadje; Tas, Latif (2018a), "Dialectics of Struggle: Challenges to the Kurdish Women's Movement”, LSE Middle East Centre Paper Series, 22. London: Middle-East-Centre. 
Al-Ali, Nadje; Tas, Latif (2018b), "Reconsidering Nationalism and Feminism: The Kurdish Political Movement in Turkey", Nations and Nationalism, 24(2), 453-473. Amrosi, Lucia (2019), "Militância política e relações de gênero: o caso das mulheres militantes do Curdistão”, Cadernos Pagu, 56, e195611. DOI: https://doi.org/10.15 90/18094449201900560011

Bandeira, Lourdes (2008), “A contribuição da crítica feminista à ciência”, Estudos Feministas, 16, 207-228.

Baris, Hanifi (2020), "Radical Democracy and Self-Governance in Kurdistan", E-International Relations, 15 de dezembro. Consultado a 15.06.2021, em https:// www.e-ir.info/2020/12/15/radical-democracy-and-self-governance-in-kurdistan/.

Bergikhani, Nazand; Hamelink, Wendelmoet; Weiss, Nerina (2018), "Theorising Women and War in Kurdistan: A Feminist and Critical Perspective”, Kurdish Studies, 6, 5-30.

Bruinessen, Martin van (2001), "From Adela Khanum to Leyla Zana: Women as Political Leaders in Kurdish History”, in Shahrzad Mojab (org.), Women of a Non-State Nation: The Kurds. Costa Mesa: Mazda Publishers, 95-112.

Çağlayan, Handan (2020), Women in the Kurdish Movement: Mothers, Comrades, Goddesses. Ithaca, NY: Palgrave Mcmillan.

Çaha, Ömer (2011), “The Kurdish Women’s Movement: A Third-Wave Feminism within the Turkish Context”, Turkish Studies, 12(3), 435-449. DOI: https://doi.org/ 10.1080/14683849.2011.604211

Cansiz, Sakine (2017), Toda mi vida fue una lucha, Tomo 1. Buenos Aires: América Libre. Tradução de Lisa Buhl.

Cansun, Şebnem (2014), "The Kurdish Female Politicians in Turkey and Their Areas of Interest”, Scottish Journal of Arts, Social Sciences and Scientific Studies, 19(1), 12-21.

Chaguri, Mariana Miggiolaro; Paniz, Flávia Xavier Muniz (2019), “Women’s War: Gender Activism in the Vietnam War and the Wars for Kurdish Autonomy", Sociologia \& Antropologia, 9, 895-918.

Collins, Patricia Hill (1997), "Comment on Hekman's Truth and Method: Feminist Standpoint Theory Revisited: Where's the Power?”, Signs, 22, 375-381.

Collins, Patricia Hill (2000), Black Feminist Thought: Knowledge, Consciousness, and the Politics of Empowerment. New York/London: Routledge.

Collins, Patricia Hill (2018), "Se perdeu na tradução? Feminismo negro, interseccionalidade e política emancipatória”, Parágrafo, 1, 6-17.

Comité de Jineologî (2017), “Jineologî: la ciencia de las mujeres”. Buenos Aires: Comité de Mujeres en Solidaridad con Kurdistán.

Dirik, Dilar (2015), “The Women's Revolution in Rojava: Defeating Fascism by Constructing an Alternative Society", in Strangers in a Tangled Wilderness (orgs.), A Small Key Can Open a Large Door: The Rojava Revolution. Wilderness: Combustion Books, 55-64. 
Dirik, Dilar (2018) “The Revolution of Smiling Women: Stateless Democracy and Power in Rojava”, in Olivia U. Rutazibwa; Robbie Shilliam (orgs.), Routledge Handbook of Postcolonial Politics. London: Routledge, 222-238.

Diyar, Zîlan (2021), "What Is Jineolojî̀?", Jineologî, 2 de janeiro. Consultado a 09.06.2021, em https://jineoloji.org/en/2018/12/14/what-is-jineoloji/.

Düzgün, Meral (2015), “The Kurdish Women’s Movement: Challenging Gendered Militarization and the Nation-State". Consultado a 08.10.2016, em https://www. academia.edu/13311456/The_Kurdish_Womens_Movement_Challenging_gendered_militarization_and_the_nation_state.

Eppel, Michael (2016), A People without a State: The Kurds from the Rise of Islam to the Dawn of Nationalism. Austin: University of Texas Press.

Ferreira, Bruna; Santiago, Vinicius (2018), “The Core of Resistance: Recognising Intersectional Struggle in the Kurdish Women's Movement”, Contexto Internacional, 40, 479-500.

Gerber, Damian; Brincat, Shannon (2018), "When Öcalan Met Bookchin: The Kurdish Freedom Movement and the Political Theory of Democratic Confederalism”, Geopolitics, 26(4), 973-997. DOI: https://doi.org/10.1080/14650045.2018.1508016

Giordano, Sara (2017), “Those Who Can't, Teach: Critical Science Literacy as a Queer Science of Failure”, Catalyst: Feminism, Theory, Technoscience, 3(1). DOI: https:// doi.org/10.28968/cftt.v3i1.28790

Güneşer, Havin (2015), “Feminicide”, in Renée In der Maur; Jonas Staal (orgs.), Stateless Democracy. Utrecht: Bak, 57-72.

Harding, Sandra (1993), "Rethinking Standpoint Epistemology: What Is 'Strong Objectivity'?”, in Linda Alcoff; Elizabeth Potter (orgs.), Feminist Epistemologies. New York/London: Routledge, 49-82.

Harding, Sandra (1996), Ciencia y feminismo. Madrid: Morata. Tradução de Pablo Manzano.

Harding, Sandra (2012), “¿Una filosofía de la ciencia socialmente relevante?: Argumentos en torno a la controversia sobre el punto de vista feminista”, in Norma Blazquez Graf; Fátima Flores Palacios; Maribel Ríos Everaldo (orgs.), Investigación feminista: epistemologia, metodologia y representaciones sociales. Ciudad de México: UNAM, 39-67. Holloway, John (2003), Mudar o mundo sem tomar o poder: o significado da revolução boje. São Paulo: Viramundo. Tradução de Paulo Barsotti.

hooks, bell (2000), Feminist Theory: From Margin to Center. London: Pluto Press.

Kaya, Gönül (2015), Por qué jineologî? Reconstruyendo una lucha universal de las mujeres. Buenos Aires: Mezopotamya.

Knapp, Michael; Flach, Anja; Ayboga, Ercan (2016), Revolution in Rojava. London: Pluto Press.

Knapp, Michael; Jongerden, Joost (2014), “Communal Democracy: The Social Contract and Confederalism in Rojava”, Comparative Islamic Studies, 10(1), 87-109. 
Kongreya Star (2018) “Goals and Principles", in The Diplomatic Relations Center of Kongreya Star, Kongreya Star and Its Committees. Consultado a 03.08.2021, em https:// rojavainformationcenter.com/storage/2021/07/Kongreya-Star-2018-Brochure.pdf. Marcus, Aliza (2007), Blood and Belief: The PKK and the Kurdish Fight for Independence. New York/London: New York University Press.

McDowall, David (1996), A Modern History of the Kurds. London: I.B. Tauris.

Miranda, Sarah Siqueira de (2016), "Por uma 'dupla revolução': movimento de mulheres curdas na luta contra a opressão étnica e de gênero". Consultado a 10.11.2019, em http://evento.abant.org.br/rba/30rba/files/1466460090_ARQUIVO_ ArtigoSarahSiqueiradeMiranda.pdf.

Mojab, Shahrazad (2003), "Kurdish Women in the Zone of Genocide and Gendercide", Al-Raida Journal, 21(103), 20-25.

Mojab, Shahrazad; Hassanpour, Amin (2021), Women of Kurdistan: A Historical and Bibliograpbic Study. London: Transnational Press.

Neven, Brecht; Schäfers, Marlene (2017), “Jineology: From Women’s Struggles to Social Liberation". Consultado a 09.06.2021, em https://roarmag.org/essays/ jineology-kurdish-women-movement.

Öcalan, Abdullah (2016a), Confederalismo democrático. Rio de Janeiro: Rizoma. Tradução de Coletivo Libertário de Apoio a Rojava.

Öcalan, Abdullah (2016b), Liberando a vida: a revolução das mulheres. São Paulo: Fundação Lauro de Campos. Tradução de Sergio Granja.

Öcalan, Abdullah (2018), Democratic Nation. Cologne: International Initiative. Tradução de International Iniciative [ed. orig. 2016].

Öcalan, Abdullah (2020), Sociology of Freedom: Manifesto of the Democratic Civilization. Los Angeles: PM Press. Tradução de Havin Guneser.

Paredes, Sebastián Estremo (2017), "La construcción de nacionalismos en el Kurdistán y la revolución del Rojava (Bakur)”. Dissertação de Mestrado em Estudos de Asia y Africa - Especialidad Medio Oriente, Centro de Estudios de Asia y África, Ciudad de México, México. Consultado a 03.12.2019, em https://repositorio.colmex.mx/ concern/theses/xp68kg47r?locale=es.

Pavicic-Ivelja, Katarina (2016), “The Rojava Revolution: Women's Liberation as an Answer to the Kurdish Question”, West Croatian History Journal, 11, 131-149.

Pazmiño, Carlos (2017), “'Desmantelar al Estado’. Elementos para entender la transición teórico-práctica del Partido de los Trabajadores del Kurdistán (PKK) hacia el confederalismo democrático”. Dissertação de Mestrado em Sociología, Facultad Latinoamericana de Ciencias Sociales, Quito, Ecuador. Consultado a 03.12.2019, em https://repositorio.flacsoandes.edu.ec/xmlui/handle/10469/12761.

Piccardi, Eleonora Gea (2021), “The Challenges of a Kurdish Ecofeminist Perspective: Maria Mies, Abdullah Öcalan, and the Praxis of Jineolojî”, Capitalism Nature Socialism, 1-20. DOI: https://doi.org/10.1080/10455752.2021.1905016 
Rivers, Daniel (2019), “Cartographies of Feminist Science Studies”, Women Studies, 48(3), 177-185. DOI: https://doi.org/10.1080/00497878.2019.1603980

Santos, Boaventura de Sousa (2019), O fim do império cognitivo. Belo Horizonte: Autêntica Editora.

Schmidinger, Thomas (2018), Rojava: Revolution, War and the Future of Syria's Kurds. London: Pluto Press.

Shahvisi, Arianne (2018), "Beyond Orientalism: Exploring the Distinctive Feminism of Democratic Confederalism in Rojava”, Geopolitics, 26(4), 998-1022. DOI: https:// doi.org/10.1080/14650045.2018.1554564

Silva, Erika (2017), “Ecofeminismos y ecologías políticas feministas”, Ecología Política, 54, 70-74.

Tank, Pinar (2017), "Kurdish Women in Rojava: From Resistance to Reconstruction”, Die Welt des Islams, 57, 404-428.

Women's Movement of Kurdistan (2020), “Kurdistan Women's Liberation Struggle”. Consultado a 20.06.2021, em https://jineoloji.org/en/2020/04/22/ kurdistan-womens-liberation-struggle/.

\section{Maria Florencia Guarche Ribeiro}

Programa de Pós-Graduação em Ciência Política, Universidade Federal do Rio Grande do Sul (UFRGS) I Pesquisadora do Conselho Nacional de Desenvolvimento Científico e Tecnológico (CNPq) Av. Bento Gonçalves, 9500, Prédio 43322 (IFCH)/Sala 205, CEP 91509900, Porto Alegre, Rio Grande do Sul, Brasil

Contacto: florenciaguarch@gmail.com

ORCID: https://orcid.org/0000-0001-5296-4387

\section{Alfredo Alejandro Gugliano}

Departamento de Ciência Política, Universidade Federal do Rio Grande do Sul (UFRGS) | Pesquisador do Conselho Nacional de Desenvolvimento Científico e Tecnológico (CNPq) Av. Bento Gonçalves, 9500, Prédio 43322 (IFCH)/Sala 205, CEP 91509900, Porto Alegre, Rio Grande do Sul, Brasil

Contacto: alfredogugliano@hotmail.com

ORCID: https://orcid.org/0000-0002-8464-8159

Artigo recebido a 30.01.2020

Aprovado para publicação a 30.06 .2021

https://doi.org/10.4000/rccs.11960 


\section{Resisting Is Living. Notes on the Kurdish Women's Political Struggle for an Anti-Patriarchal Society in the $21^{\text {st }}$ Century}

The purpose of this article is to discuss the particularities of the women's movement in Kurdistan and its contribution regarding debates on alternative forms of democracy. We assume that this experience, along with other trajectories identified with decolonial feminism and black feminism, is reshaping the struggle of women as the vanguard of a new type of emancipatory movement. The results of this study indicate that the empowerment and mutual benefit actions promoted by the generation of associative networks, encouraged by the autonomous organization of female guerrilla cadres, altered the self-perception of women in Kurdish communities. As a result, social and political power dynamics previously existing in the region have been modified. Keywords: feminism; Kurdistan; political activism; social movements; women.

\section{Résister c'est vivre. Notes sur la lutte politique des femmes kurdes pour une société antipatriarcale au xxıe siècle}

Dans cet article nous proposons de discuter les particularités du mouvement des femmes au Kurdistan et sa contribution en termes des débats sur les formes alternatives de démocratie. Nous partons du principe que cette expérience, avec d'autres trajectoires identifiées avec le féminisme colonialiste et le féminisme noir, est en train de redimensionner la lutte des femmes en tant qu'avant-garde d'un nouveau type de mouvement émancipateur. Les résultats de l'étude indiquent que les actions de l'empouvoirement et de bénéfice mutuelles promues par la création de réseaux associatifs, encouragés par l'organisation autonome des cadres féminins de la guérilla, ont modifié l'autoperception des femmes dans les communautés kurdes. Ainsi, les dynamiques de pouvoir social et politique existant antérieurement dans la région ont été modifiées.

Mots-clés: activisme politique; féminisme; femmes; Kurdistan; mouvements sociaux. 
